\title{
Severity of dissociative experiences and emotion dysregulation mediate the relationship between childhood trauma and Internet addiction symptom severity among young adults
}

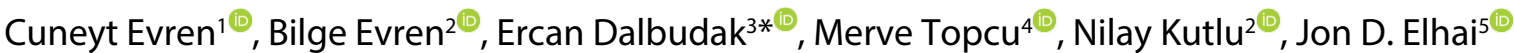

'Bakirkoy Training and Research Hospital for Psychiatry Neurology and Neurosurgery, Research, Treatment and Training Center for Alcohol and Substance Dependence (AMATEM), Istanbul - Turkey

${ }^{2}$ Baltalimani State Hospital for Musculoskeletal Disorders, Department of Psychiatry, Istanbul - Turkey

${ }^{3}$ Private Practice, Ankara - Turkey

${ }^{4}$ Cankaya University, Department of Psychology, Ankara - Turkey

${ }^{5}$ University of Toledo, Department of Psychology and Department of Psychiatry, Toledo, OH - USA

\begin{abstract}
Objective: The first aim of the present study was to evaluate the relationship between childhood trauma and Internet addiction (IA) symptom severity. The second aim was to evaluate the mediator effects of dissociative experiences and emotion dysregulation on this relationship.

Method: We conducted the study using an online survey with 920 university student participants. Participants were evaluated with the Internet Addiction Test (IAT), Dissociative Experiences Scale (DES), Childhood Trauma Questionnaire (CTQ-28), and Difficulties in Emotion Regulation Scale (DERS).

Results: Compared with participants evidencing low IA risk $(n=806,87.6 \%)$, those with high IA risk $(n=114,12.4 \%)$ had a longer duration of daily Internet use and a higher rate of problems related to Internet use. The high IA risk group was connected to the Internet less through a smartphone and more through computer use. In addition, scale scores (DES, DERS and CTQ-28) were higher among the group with high IA risk. Scale scores were mildly to moderately correlated with each other. In linear regression analysis, childhood trauma (particularly emotional abuse and physical neglect) was related to severity of IA symptoms. Severity of dissociative experiences and emotion dysregulation mediated the childhood trauma-IA symptom relationship.

Conclusion: These findings suggest relations between the severity of childhood trauma, particularly emotional abuse and physical neglect dimensions, and severity of IA symptoms among Turkish young adults. Severity of dissociative experiences and emotion dysregulation may also partially mediate this relationship.
\end{abstract}

Keywords: Childhood trauma, dissociative experiences, emotion dysregulation, emotional abuse, internet addiction

How to cite this article: Evren C, Evren B, Dalbudak E, Topcu M, Kutlu N, Elhai JD. Severity of dissociative experiences and emotion dysregulation mediate the relationship between childhood trauma and Internet addiction symptom severity among young adults. Dusunen Adam The Journal of Psychiatry and Neurological Sciences 2019;32:334-344.

Correspondence: Ercan Dalbudak, Private Practice, Sehit Adem Yavuz No: 6/6-7 Çankaya, Ankara - Turkey

Phone: +90 5056478616 E-mail: edalbudak @hotmail.com

Received: July 29, 2019; Revised: August 29, 2019; Accepted: September 05, 2019 


\section{INTRODUCTION}

Although the usefulness of the Internet is evident in many areas of life, especially in the academic field and for recreational purposes, a loss of control over Internet use may have a negative impact on daily life functioning (e.g., academic impairment, decreased productivity), family relationships, and emotional stability (1). This phenomenon has been termed "problematic Internet use," "pathological Internet use," and "Internet addiction (IA)." Although there is no consensus over the use of the term "IA" and a standardized definition has not been uniformly agreed on, IA can be defined as excessive, uncontrolled and harmful use of the Internet (1). The rates of IA among adolescents and young people range from $2.4 \%$ to $37.9 \%$ in Asia, and between $3.1 \%$ and $18.3 \%$ in Europe (2). Previous studies in Turkey demonstrated that the rates of IA can vary even according to the university where the sample is enrolled, with results of $12.3 \%$ (3), 9.7\% (4), $7.2 \%$ (1), or lastly $10 \%(5)$.

Childhood traumas were found related to substance addiction (6-9) as well as behavioral addictions such as gambling (10,11), Internet gaming disorder (IGD) (12), and IA (5,13-15). However, only four studies investigated the association between childhood traumas and IA. Zhang et al. $(14,15)$ reported that physical abuse is a possible risk factor for IA among high-school students, whereas Yates et al. (13) suggested that maltreated youth are at disproportionate risk for IA. More recent work conducted by Dalbudak et al. (5) reported that although childhood traumas, in particular physical neglect, emotional neglect, and emotional abuse, were found related to the severity of IA risk, the most important predictor being emotional abuse. Finally, in their recent study Kircaburun et al. (12) found an indirect relationship between childhood emotional trauma and IGD; online gamers with a history of emotional abuse and/or neglect had higher levels of depressive symptoms, and depressive symptomatology was an important risk factor for IGD.

Childhood trauma, particularly emotional neglect was suggested to have significant effect on dissociative disorders among Turkish college students (16). Dissociative symptoms may accompany not only substance addiction $(17,18)$ but also behavioral addictions such as pathological gambling (11) and IA $(4,5,19,20)$. The association between IA and dissociative symptoms was noted in both the clinical (19) and nonclinical populations $(4,5,20)$. Both Canan et al. (4) and Dalbudak et al. (5) suggested that IA was associated with higher levels of dissociative experiences among Turkish university students.

Exposure to traumatic events and interpersonal trauma in childhood is associated with wide-ranging psychosocial, developmental, and medical impairments in children, adolescents, and adults, with emotional dysregulation being a core feature that may help account for this heightened risk (21). Emotion regulation refers to the modulation of emotional arousal, the awareness, understanding, and acceptance of emotions, as well as the ability to act in desired ways regardless of emotional state (22). In recent years, increasing attention has been given to emotion dysregulation as a potentially common feature of many forms of addiction (23), including substance addictions such as smoking, alcohol, or drugs (24-26), and behavioral addictions such as risky sexual behaviors $(27,28)$, gambling addiction (29-31), video game addiction (32), IGD (33), disordered online social networking use (34) and IA (35).

Some researchers have suggested that individuals who possess deficits in emotion regulation are more prone to regulate negative emotions by indulging in activities that offer immediate pleasure $(36,37)$. Consistent with this suggestion, individuals who have emotion dysregulation are more likely to engage in addictive behaviors in an attempt to escape from, or minimize, negative moods and/or try alleviate distressing feelings (38), whereas emotional intelligence has been demonstrated as a protective factor for online gaming addiction (39).

Early speculation by Young and Rogers (40) suggested that Internet use has a propensity to alleviate dysphoric moods and may therefore be used to cope with real-life problems. Later studies demonstrated significant associations between using the Internet to manage emotions, difficulty regulating Internet use, and negative outcomes of Internet use (41-45). Furthermore, studies have shown difficulties in emotion regulation to be associated with problematic Internet use $(32,35,38,46-49)$

The aim of the present study was to evaluate the relationship between severity of childhood trauma and IA symptom severity. Previous studies revealed that emotion dysregulation and dissociation are mediators in the association between childhood trauma and other variables such as eating psychopathology (50), internalized and externalized behavior problems (51) and gambling severity (11). This suggests that while evaluating the association between childhood trauma and other variables, such as IA symptom severity, it is 
important to evaluate mediating effects of emotion dysregulation and dissociation. Thus, in relation to our second aim, the novelty of the present study is that, although there are some studies that evaluated the relationship between childhood trauma and IA symptom severity, this is the first study to evaluate the mediator effects of dissociative experiences and emotion dysregulation on this relationship. We hypothesized that severity of dissociative experiences and emotion dysregulation may mediate this relationship.

\section{METHOD}

\section{Participants and procedure}

An online survey using a cross-sectional design was conducted with Turkish university students in Ankara, Turkey. The study procedures were carried out in accordance with the Declaration of Helsinki. The study protocol was approved by the Ethics Committee of Cankaya University (Turkey) and the study was anonymous and confidential. After reading the Plain Language Information Statement, informed consent was obtained from all participants. Participants sampled from Cankaya University who agreed to participate in the study were rewarded with bonus credit, which added to their overall grade for particular courses in which they were enrolled. Furthermore, participants were informed that they would not be penalized for declining participation and/or abandoning the study once they started. Overall, the data collection stage spanned from December 11, 2018 to January 14, 2019.

A total of 1,112 potential participants initiated the online survey and they all provided informed consent. Among these, 192 participants did not fill in any of the scales, and thus a total of 920 participants were included in the present study.

\section{Measures}

Internet Addiction Test (IAT): The IAT consists of 20 items rated on a six-point Likert scale, ranging from 0 (does not apply) to 5 (always applies) (52). The IAT includes questions such as "How often do you find that you stay online longer than you intended?" A cut-off value of 50 or higher has been suggested as indicative of problematic Internet use and a score of 80 or higher is indicative of pathological use $(52,53)$. The Turkish version of the IAT, which was used in the present study, with high internal consistency $(\alpha=0.93)$ and temporal reliability $(\alpha=0.87)$, revealed promising and sound psychometric properties (54). Cronbach's a coefficient was 0.93 in the present study.

Dissociative Experiences Scale (DES): Dissociative symptoms were assessed using the 28 -item self-report DES (55). The DES is not a diagnostic tool but serves as a screening device for chronic dissociative disorders. Respondents are asked to rate various dissociative experiences occurring in their daily life when they are not under the influence of alcohol or drugs. For each item, possible scores range from 0 to 100 . The DES has three subscales. The amnestic dissociation subscale includes items 3, 4, 5, 6, 8, 10, 25, and 26. The absorption and imaginative involvement subscale includes items 2 , $14,15,16,17,18,20,22$, and 23 . The depersonalization and derealization subscale includes items $7,11,12,13$, 27 , and 28 . The DES is a highly reliable and internally consistent questionnaire. The Turkish version of the scale has reliability and validity similar to its original form $(56,57)$. Cronbach's a coefficient was 0.95 in the present study.

Childhood Trauma Questionnaire (CTQ-28): The CTQ $(58,59)$ is a 28 -item retrospective self-report instrument that inquires about traumatic experiences during childhood and adolescence. It assesses five types of childhood trauma: emotional abuse, emotional neglect, physical abuse, physical neglect, and sexual abuse. The CTQ has excellent test-retest reliability and convergent validity $(58,59)$. Each item is rated from 1 (never) to 5 (very often). Scores range from 5 to 25 for each type of trauma and 25 to 125 for the total trauma exposure score. The Turkish version of the CTQ was validated in a previous study (60) and Cronbach's a coefficient was 0.81 in the present study.

Difficulties in Emotion Regulation Scale (DERS): The DERS is a 36 -item measure that provides a comprehensive assessment of overall emotion dysregulation, as well as six specific dimensions: nonacceptance of negative emotions, difficulties engaging in goal-directed behaviors when distressed, difficulties controlling impulsive behaviors when distressed, limited access to effective emotion regulation strategies, lack of emotional awareness, and lack of emotional clarity. The DERS has demonstrated good test-retest reliability and adequate construct and predictive validity $(22,61)$, and is strongly correlated with an experimental measure of emotion regulation among BPD patients $(\mathrm{r}=-0.63)$ (62). The Turkish version of the DERS has been validated (63). In the present study, the DERS total score was used as an index of the overall level of emotion dysregulation; its Cronbach's $\alpha$ coefficient was 0.93 . 


\section{Data analysis}

SPSS 17.0 for Windows (IBM, Chicago IL) was used for all analyses. We formed the groups according to a cutoff value of 80 or higher on the IAT, which is indicative of pathological use $(52,53)$. We used Student's t-tests to compare the groups on continuous variables. Categorical sociodemographic variables were compared by means of $\chi^{2}$ statistics. Using the severity of IA symptoms as the dependent variable and severity of childhood trauma, dissociative experiences and emotion dysregulation as independent variables, hierarchical multiple linear (stepwise) regression models were performed. For all statistical analyses, $p$ values were two-tailed, and differences were considered significant at $\mathrm{p}<0.05$.

\section{RESULTS}

Participants scoring 80 or higher on the IAT constituted the group with high IA risk $(\mathrm{n}=114,12.4 \%)$ and those with a score of 79 or less constituted the group with low IA risk $(\mathrm{n}=806,87.6 \%)$.

\section{Sociodemographic variables}

Age, gender and marital status did not differ between the group with high IA risk and the group with low IA risk (Table 1$)$. Mean age $( \pm$ SD) was 21.69 years $( \pm 2.21)$ for the group with high IA risk and $22.19( \pm 4.26)$ for the group with low IA risk. The rate of males was $31.6 \%$ among the group with high IA, whereas this rate was $33.0 \%$ among the group with low IA risk $\left(\chi^{2}=0.092\right.$, $\mathrm{p}=0.762)$. Among both the group with high IA $(95.6 \%)$ and the group with low IA risk $(94.5 \%)$, the rates of singles were high $\left(\chi^{2}=1.405, \mathrm{p}=0.704\right)$.

\section{Clinical variables}

Age at first Internet use $\left(\chi^{2}=6.771, \mathrm{p}=0.148\right)$ and mobile Internet use $\left(\chi^{2}=1.070, p=0.301\right)$ did not differ between the group with high IA risk and the group with low IA risk (Table 1). Duration of daily Internet use was longer in the high IA risk group $\left(\chi^{2}=51.243, \mathrm{p}<0.001\right)$. Among this group, $38.6 \%$ reported that they use the Internet more than 6 hours per day, whereas this rate was $14.0 \%$ among those with low IA risk. Similarly, problems related to Internet use were higher in the high IA risk group $(72.8 \%)$ than the group with low IA risk (33.6\%) $\left(\chi^{2}=64.778, \mathrm{p}<0.001\right)$. In addition, among participants who reported having problems related to Internet use, the rate of those who reported that these problems began before age 18 was higher in the high IA risk group (55.4\%) than among those with low IA risk $\left(\chi^{2}=8.622, \mathrm{p}=0.003\right)$. This high risk group was connected to the Internet less through a smartphone and more through computer use $\left(\chi^{2}=13.770, \mathrm{p}=0.008\right)$ (Table 1).

\section{Scale scores}

Scale scores (DES $[t=-7.499, \mathrm{p}<0.001]$, DERS $[\mathrm{t}=-9.612$, $\mathrm{p}<0.001]$ and CTQ-28 [ $\mathrm{t}=-5.240, \mathrm{p}<0.001])$ were higher among the group with high IA risk. In addition, subscales scores of these scales were higher among the group with high IA risk (Table 2). Scale and subscale scores were mildly to moderately correlated with each other (Table 3).

\section{Linear regression analyses}

Taken the severity of IAT score as a dependent variable, series of linear (stepwise) regression analyses were conducted. In the first model, first step, severity of childhood trauma was entered in the analysis as an independent variable, where it was related to the severity of IA symptoms. In the second step of this model, five types of childhood trauma were entered in the analysis as independent variables instead of CTQ-28 total score. In this analysis, emotional abuse and physical neglect were related with the severity of IA symptoms (Table 4 ).

In the first step of the second model, total DES score was entered in the analysis in addition to emotional abuse and physical neglect, and it was related with the severity of IA symptoms, together with emotional abuse, whereas physical neglect was no more related with the severity of IA symptoms. In the second step of this model, instead of total DES score, subscales of DES were entered in the analysis in addition to emotional abuse and physical neglect. In this analysis, amnestic dissociation (DES-I) and absorption and imaginative involvement (DES-II) subscales of DES together with emotional abuse were related with the severity of IA symptoms (Table 4 ).

In the first step of the third Model, total DERS score was entered in the analysis in addition to emotional abuse and physical neglect, and it was related with the severity of IA symptoms, together with both emotional abuse and physical neglect. In the second step of this model, instead of total DERS score, subscales of DERS were entered in the analysis in addition to emotional abuse and physical neglect. In this analysis, strategies, impulse, clarity and aware subscales of DERS were related with the severity of IA symptoms, together with physical neglect, whereas emotional abuse was no more related with the severity of IA symptoms (Table 4). 
Table 1: Comparing sociodemographic and clinical variables according to the Internet addiction risk severity

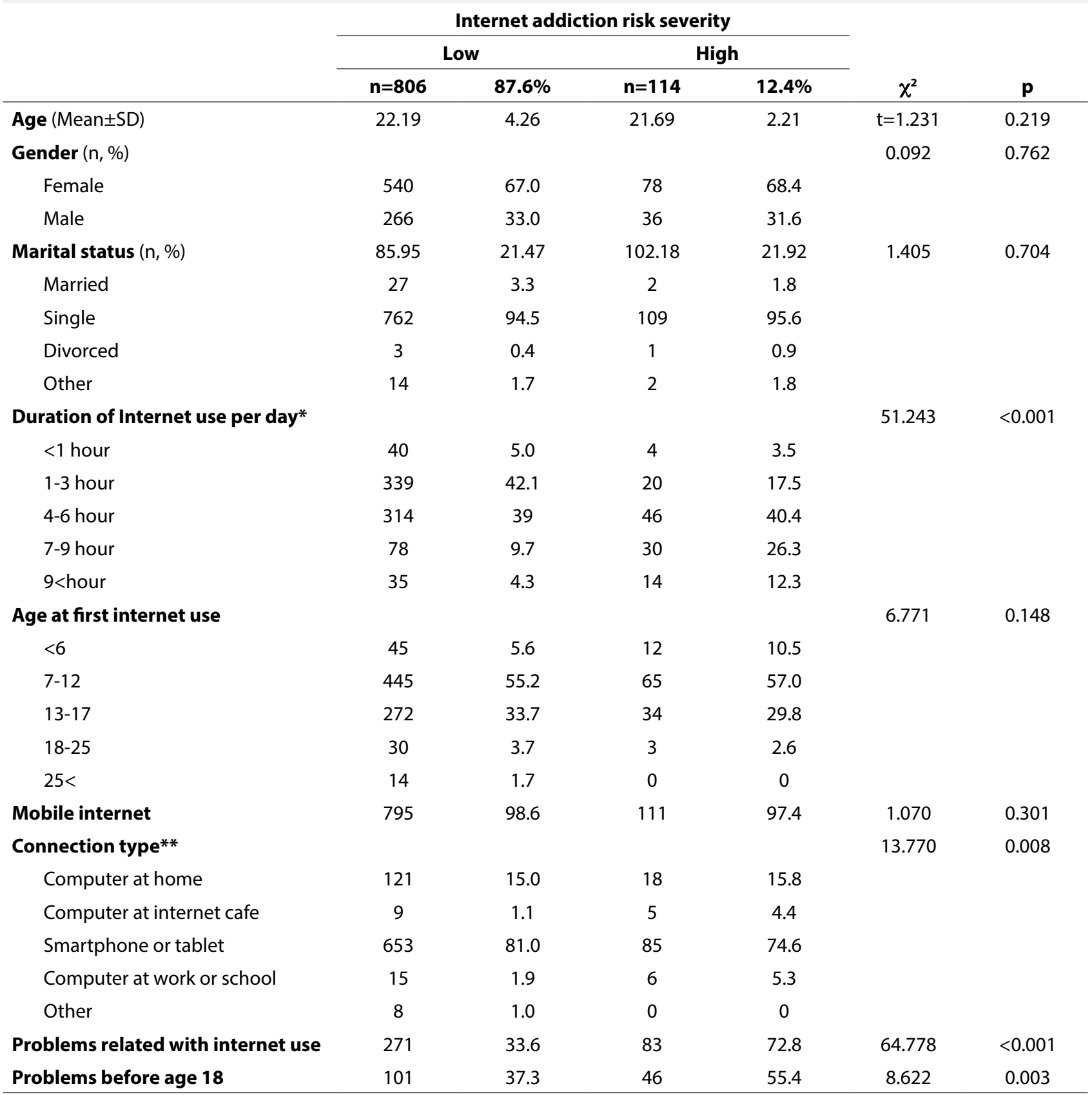

*How many hours did you use the Internet (non-business/non-academic) on an average day over the last year?

**How did you connect to the Internet in the last 12 months?

In the first step of the fourth model, total DES and DERS scores were entered in the analysis in addition to emotional abuse and physical neglect, and they were related with the severity of IA symptoms, whereas emotional abuse and physical neglect were no more related with the severity of IA symptoms. In the second step of this model, instead of total DES and DERS scores, subscales of these scales were entered in the analysis in addition to emotional abuse and physical neglect. In this analysis, amnestic dissociation (DES-I) subscale of DES and strategies, impulse, clarity and aware subscales of DERS were related with the severity of IA symptoms, whereas emotional abuse and physical neglect were not (Table 4).

Severity of dissociative experiences (particularly amnestic dissociation [DES-I]), and emotion dysregulation (particularly strategies, impulse, clarity and aware subscales) mediated the relationship of childhood traumas of emotional abuse and physical neglect with the severity of IA symptoms (Table 4). 
Table 2: Comparing scale scores according to Internet addiction risk severity Internet addiction risk severity

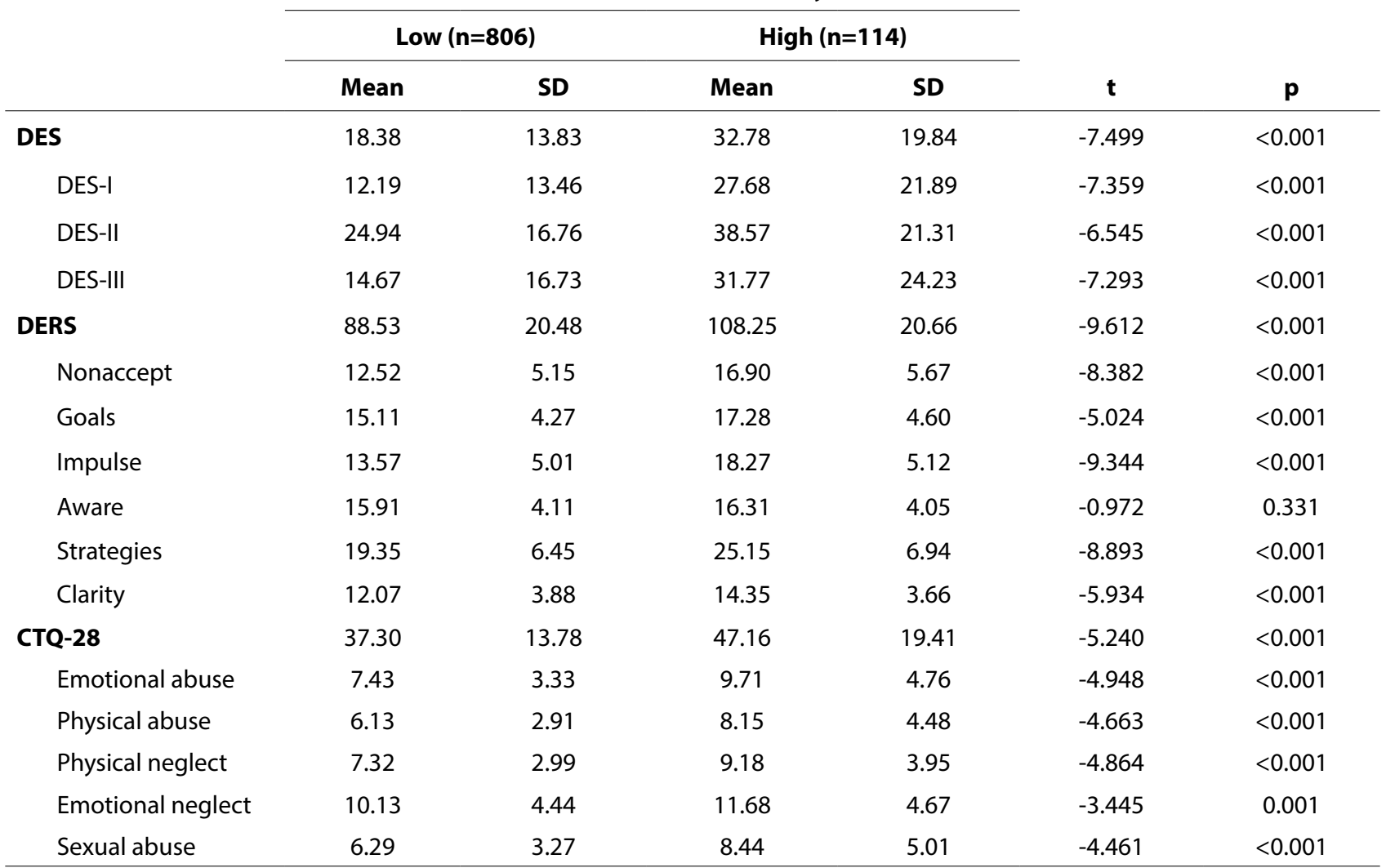

DES: Dissociative Experiences Scale, DES-I: Amnestic dissociation, DES-II: Absorption and imaginative involvement, DES-III: Depersonalization and derealization, DERS: Difficulties in Emotion Regulation Scale, CTQ-28: Childhood Trauma Questionnaire

Table 3: Correlation coefficients between the scale scores

\begin{tabular}{|c|c|c|c|c|}
\hline & IAT & DES & CTQ-28 & DERS \\
\hline DES & 0.431 & 1 & 0.457 & 0.449 \\
\hline DES-I & 0.431 & 0.878 & 0.539 & 0.390 \\
\hline DES-II & 0.377 & 0.917 & 0.307 & 0.415 \\
\hline DES-III & 0.383 & 0.902 & 0.443 & 0.431 \\
\hline CTQ-28 & 0.294 & 0.457 & 1 & 0.370 \\
\hline Emotional abuse & 0.290 & 0.434 & 0.886 & 0.381 \\
\hline Physical abuse & 0.248 & 0.389 & 0.851 & 0.281 \\
\hline Physical neglect & 0.274 & 0.419 & 0.850 & 0.306 \\
\hline Emotional neglect & 0.189 & 0.288 & 0.742 & 0.299 \\
\hline Sexual abuse & 0.230 & 0.385 & 0.824 & 0.258 \\
\hline DERS & 0.408 & 0.449 & 0.370 & 1 \\
\hline Nonaccept & 0.338 & 0.383 & 0.340 & 0.775 \\
\hline Goals & 0.239 & 0.229 & $0.039^{*}$ & 0.627 \\
\hline Impulse & 0.381 & 0.436 & 0.368 & 0.832 \\
\hline Aware & $0.050^{*}$ & $0.060^{*}$ & 0.214 & 0.380 \\
\hline Strategies & 0.370 & 0.390 & 0.293 & 0.873 \\
\hline Clarity & 0.303 & 0.358 & 0.291 & 0.691 \\
\hline
\end{tabular}

IAT: Internet Addiction Test, DES: Dissociative Experiences Scale, DES-I: Amnestic dissociation, DES-II: Absorption and imaginative involvement,

DES-III: Depersonalization and derealization, CTQ-28: Childhood Trauma Questionnaire, DERS: Difficulties in Emotion Regulation Scale. * $p>0.05$, all the rest is $\mathrm{p}<0.001$ 
Table 4: Predictors of severity of Internet addiction in linear regression (stepwise) analysis

\begin{tabular}{|c|c|c|c|c|c|c|}
\hline \multirow[t]{2}{*}{ Mode } & & \multicolumn{2}{|c|}{ Unstandardized coefficients } & \multirow{2}{*}{$\begin{array}{c}\begin{array}{c}\text { Standardized } \\
\text { coefficients }\end{array} \\
\text { Beta }\end{array}$} & \multirow[b]{2}{*}{$\mathbf{t}$} & \multirow[b]{2}{*}{$\mathbf{p}$} \\
\hline & & B & Std. Error & & & \\
\hline $1 \mathrm{a}$ & CTQ-28 & 0.326 & 0.035 & 0.294 & 9.317 & $<0.001$ \\
\hline \multirow[t]{2}{*}{$1 b$} & Emotional abuse & 0.895 & 0.189 & 0.195 & 4.748 & $<0.001$ \\
\hline & Physical neglect & 0.769 & 0.214 & 0.147 & 3.588 & $<0.001$ \\
\hline \multirow[t]{3}{*}{$2 \mathrm{a}$} & Emotional abuse & 0.428 & 0.183 & 0.093 & 2.342 & 0.019 \\
\hline & Physical neglect & 0.315 & 0.206 & 0.060 & 1.528 & 0.127 \\
\hline & DES & 0.392 & 0.036 & 0.365 & 10.903 & $<0.001$ \\
\hline \multirow[t]{4}{*}{$2 b$} & Emotional abuse & 0.440 & 0.182 & 0.096 & 2.423 & 0.016 \\
\hline & Physical neglect & 0.165 & 0.220 & 0.032 & 0.752 & 0.452 \\
\hline & DES-I & 0.280 & 0.049 & 0.263 & 5.728 & $<0.001$ \\
\hline & DES-II & 0.148 & 0.038 & 0.160 & 3.934 & $<0.001$ \\
\hline \multirow[t]{3}{*}{$3 a$} & Emotional abuse & 0.406 & 0.184 & 0.088 & 2.205 & 0.028 \\
\hline & Physical neglect & 0.585 & 0.203 & 0.112 & 2.878 & 0.004 \\
\hline & DERS & 0.263 & 0.025 & 0.340 & 10.583 & $<0.001$ \\
\hline \multirow[t]{6}{*}{$3 b$} & Emotional abuse & 0.321 & 0.184 & 0.070 & 1.742 & 0.082 \\
\hline & Physical neglect & 0.684 & 0.204 & 0.131 & 3.348 & 0.001 \\
\hline & Strategies & 0.348 & 0.106 & 0.142 & 3.285 & 0.001 \\
\hline & Impulse & 0.518 & 0.138 & 0.164 & 3.757 & $<0.001$ \\
\hline & Clarity & 0.618 & 0.158 & 0.146 & 3.917 & $<0.001$ \\
\hline & Aware & -0.378 & 0.132 & -0.093 & -2.857 & 0.004 \\
\hline \multirow[t]{4}{*}{$4 a$} & Emotional abuse & 0.177 & 0.180 & 0.039 & 0.981 & 0.327 \\
\hline & Physical neglect & 0.287 & 0.200 & 0.055 & 1.435 & 0.151 \\
\hline & DES & 0.298 & 0.037 & 0.278 & 8.068 & $<0.001$ \\
\hline & DERS & 0.195 & 0.025 & 0.252 & 7.653 & $<0.001$ \\
\hline \multirow[t]{7}{*}{$4 b$} & Emotional abuse & 0.168 & 0.178 & 0.037 & 0.942 & 0.346 \\
\hline & Physical neglect & 0.097 & 0.210 & 0.019 & 0.462 & 0.644 \\
\hline & DES-I & 0.312 & 0.038 & 0.293 & 8.286 & $<0.001$ \\
\hline & Strategies & 0.326 & 0.102 & 0.134 & 3.192 & 0.001 \\
\hline & Impulse & 0.507 & 0.153 & 0.120 & 3.321 & 0.001 \\
\hline & Clarity & 0.350 & 0.134 & 0.111 & 2.600 & 0.009 \\
\hline & Aware & -0.327 & 0.128 & -0.081 & -2.558 & 0.011 \\
\hline
\end{tabular}

CTQ-28: Childhood Trauma Questionnaire, DES: Dissociative Experiences Scale, DES-I: Amnestic dissociation, DES-II: Absorption and imaginative involvement, DES-III: Depersonalization and derealization, DERS: Difficulties in Emotion Regulation Scale, Model (1a) F=19.711, df=5, 914, p<0.001, Adjusted R2=0.092, Model (1b) $\mathrm{F}=49.268, \mathrm{df}=2,917, \mathrm{p}<0.001$, Adjusted $\mathrm{R}^{2}=0.095$, Model (2a) $\mathrm{F}=76.693, \mathrm{df}=3,916, \mathrm{p}<0.001$, Adjusted R $\mathrm{R}^{2}=0.198$, Model $(2 \mathrm{~b}) \mathrm{F}=60.935$, df $=4,915, \mathrm{p}<0.001$, Adjusted $R^{2}=0.207$, Model (3a) $F=74.152, d f=3,916, p<0.001$, Adjusted $R^{2}=0.193$, Model (3b) $F=40.675, d f=6,913, p<0.001$, Adjusted $R^{2}=0.206$, Model (4a) $F=75.777$, $\mathrm{df}=4,915, \mathrm{p}<0.001$, Adjusted $\mathrm{R}^{2}=0.246$, Model (4b) $\mathrm{F}=47.257, \mathrm{df}=7,912, \mathrm{p}<0.001$, Adjusted $\mathrm{R}^{2}=0.261$

\section{DISCUSSION}

The rate of high IA risk was $12.4 \%$ in the present study, which was consistent with previous studies that considered IA dichotomously (IA present or absent) in analyses and found rates ranging from 7.2 to 12.3 among university students in Turkey (1,3-5). The main finding of the present study, which is also consistent with our hypothesis, was that severity of childhood trauma and IA symptoms were related, and severity of dissociative experiences (particularly amnestic dissociation [DES-I]) and emotion dysregulation (particularly strategies, impulse, clarity and aware subscales) mediated this relationship. This finding is consistent with previous studies that found both emotion dysregulation and dissociation to be significant mediators between childhood trauma and eating psychopathology (50), internalized and externalized 
behavior problems (51), and gambling severity (11). This may suggest that young adults with high dissociative experiences and emotional dysregulation, may enjoy using the Internet, which may offer them immediate pleasure to regulate negative emotions.

Severity of childhood trauma and severity of different trauma types were all higher among those with high IA risk. Although severity of childhood trauma was related with the severity of IA symptoms in regression analysis, subsequent analysis revealed that among different forms of childhood trauma, particularly emotional abuse and physical neglect dimensions are related to the severity of IA symptoms. This may suggest that instead of particularly focusing on physical and sexual abuse, it is important to evaluate all forms of childhood trauma when considering IA (5). This is important because, directly or indirectly, childhood traumas can contribute to the formation of other psychopathologies such as dissociative experiences or disorders $(16,18,64-66)$ and behavioral addictions such as gambling $(10,11)$, IGD (12) and IA (5,13-15), with emotional dysregulation being a core feature that may help account for this heightened risk (21).

In a previous study, physical abuse was reported to be a possible risk factor for IA among Chinese students (14). Nevertheless, causal relationships between physical abuse and IA may be in a reverse sequence in this study. In the present study, one of the two main forms of childhood trauma that was related to severity of IA was emotional abuse. Consistent with this finding, a previous study conducted in Europe revealed that adolescents lacking emotional and psychological support had the highest risk for IA (2). In addition, emotional abuse was found to be a possible risk factor for IA among Turkish university students (5). Supporting these findings, Gladstone et al. (67) pointed out that the significance of emotional abuse as an important development factor was linked with adulthood problems in self-definition and self-worth. The results of previous studies showed that lower family functioning was related with IA (68), whereas a warm family atmosphere was found to be a protective factor against IA among college students (69). Furthermore, early emotional abuse may be related to personality dimensions associated with poor impulse control and interpersonal relationships and may increase the risk of emotional and cognitive problems (70) and vulnerability to severe addiction (71).

Consistent with previous studies $(4,5,19,20)$, severity of dissociative experiences, which is suggested to be a maladaptive strategy to alleviate painful emotions in students (72), were related to severity of IA in the present study. Students with negative emotions may use both dissociation (72) and/or the Internet (73-75) to relieve these emotions both internally and externally. That is, dissociation may (at least theoretically) be associated with unique characteristics of Internet use (e.g., anonymity) (4). Thus the Internet may provide an appropriate place for students with severe childhood trauma to dissociate from, and in other words manage, their negative emotions. Findings from the present study may suggest that dissociative experiences among persons with high IA risk may represent pathological dissociation directly related with childhood trauma or a possible psychological defense mechanism that university students with severe childhood trauma frequently use against internal or external stress. Nevertheless, the cross-sectional design of the present study makes it difficult to interpret the findings.

Our findings that individuals with Internet or online social network addiction were more likely to report problems with emotion regulation are consistent with the literature $(34,35,38,46-49)$. The reason for these findings may be that use of the Internet might serve as an emotion-regulating function for young adults with emotion dysregulation (73-75), by helping them distract from negative emotions or regulate feelings of loneliness, further increasing their likelihood of having IA (49). It was further suggested that emotion dysregulation might be more powerful in driving symptoms of IA compared to negative emotionality (46). The finding that emotion dysregulation is a significant determinant of IA provides important implications that IA could be prevented by providing training to improve young adults' emotion regulation skills. Training in emotion regulation has been included as an important component in various therapeutic approaches, such as emotion-focused therapy (76), acceptance- and mindfulness-based therapy (77), and emotion regulation therapy (23).

There are several limitations of the present study that should be noted. First of all, participants were nonclinical volunteers and all scales were self-rated. Secondly, we did not screen for common comorbidities such as impulse control disorders and gambling disorder, which may be considered as a limitation. Third, because of the shortcoming of the sociodemographic form, which included only information of marital status, gender, and age, detailed information about significant variables, such as previous diagnoses, consumption of any medicines, and substance abuse could not be provided. Finally, since this study is cross-sectional, the findings cannot address the causal relationships among the 
primary constructs of interest.

To conclude, the present study supported previous findings demonstrating that the severity of childhood trauma, particularly emotional abuse and physical neglect dimensions, and severity of IA symptoms are associated in Turkish young adults (5). As suggested by previous studies that evaluated childhood trauma in different populations $(11,50,51)$ and a population similar to ours (5), the present study indicates that multiple forms of childhood trauma should be assessed for individuals with pathological Internet use. We also found that severity of dissociative experiences and emotion dysregulation may have partial mediating effects on this relationship. This finding suggests that these considerations are important in understanding the pathophysiology of the relationship between childhood trauma and IA, but at the same time they might offer potential treatment targets. The present study may suggest that in order to tackle IA among young adults, clinicians need to address childhood trauma, dissociative experiences, and emotion regulation competencies, which are potentially important components to be considered in IA intervention programs for reducing IA.

\begin{tabular}{|c|c|c|}
\hline \multicolumn{2}{|c|}{ Contribution Categories } & \multirow{2}{*}{\begin{tabular}{|l|} 
Author Initials \\
C.E., B.E., E.D., J.D.E.
\end{tabular}} \\
\hline \multirow{3}{*}{ Category 1} & Concept/Design & \\
\hline & Data acquisition & M.T., N.K. \\
\hline & Data analysis/Interpretation & C.E. \\
\hline \multirow{2}{*}{ Category 2} & Drafting manuscript & C.E., B.E., E.D. \\
\hline & Critical revision of manuscript & C.E. \\
\hline Category 3 & Final approval and accountability & $\begin{array}{l}\text { C.E., B.E., E.D., M.T., N.K. } \\
\text { J.D.E. }\end{array}$ \\
\hline \multirow{2}{*}{ Other } & Technical or material support & C.E. \\
\hline & Supervision & C.E., J.D.E. \\
\hline
\end{tabular}

Ethics Committee Approval: The study protocol was approved by the Ethics Committee of Cankaya University (Turkey).

Informed Consent: Written informed consent was obtained from the patients.

Peer-review: Externally peer-reviewed.

Conflict of Interest: None declared.

Financial Disclosure: None declared.

\section{REFERENCES}

1. Dalbudak E, Evren C, Aldemir S, Coskun KS, Ugurlu H, Yildirim FG. Relationship of Internet addiction severity with depression, anxiety, and alexithymia, temperament and character in university students. Cyberpsychol Behav Soc Netw 2013; 16:272-278. [CrossRef]
2. Durkee T, Kaess M, Carli V, Parzer P, Wasserman C, Floderus B, Apter A, Balazs J, Barzilay S, Bobes J, Brunner R, Corcoran P, Cosman D, Cotter P, Despalins R, Graber N, Guillemin F, Haring C, Kahn JP, Mandelli L, Marusic D, Meszaros G, Musa GJ, Postuvan V, Resch F, Saiz PA, Sisask M, Varnik A, Sarchiapone M, Hoven CW, Wasserman D. Prevalence of pathological internet use among adolescents in Europe: demographic and social factors. Addiction 2012; 107:2210-2222. [CrossRef]

3. Kayri M, Gunuc S. The adaptation of Internet addiction scale into Turkish: the study of validity and reliability. Ankara University, Journal of Faculty of Educational Sciences 2009; 42:157-175. (Turkish) [CrossRef]

4. Canan F, Ataoglu A, Ozcetin A, Icmeli C. The association between Internet addiction and dissociation among Turkish college students. Compr Psychiatry 2012; 53:422-426. [CrossRef]

5. Dalbudak E, Evren C, Aldemir S, Evren B. The severity of Internet addiction risk and its relationship with the severity of borderline personality features, childhood traumas, dissociative experiences, depression and anxiety symptoms among Turkish university students. Psychiatry Res 2014; 219:577-582. [CrossRef]

6. Evren C, Kural S, Cakmak D. Clinical correlates of childhood abuse and neglect in substance dependents. Addict Behav 2006; 31:475-485. [CrossRef]

7. Dube SR, Miller JW, Brown DW, Giles WH, Felitti VJ, Dong M, Anda RF. Adverse childhood experiences and the association with ever using alcohol and initiating alcohol use during adolescence. J Adolesc Health 2006; 38:444.e1-10. [CrossRef]

8. Zlotnick C, Shea MT, Recupero P, Bidadi K, Pearlstein T, Brown P. Trauma, dissociation, impulsivity, and self-mutilation among substance abuse patients. Am J Orthopsychiatry 1997; 67:650654. [CrossRef]

9. Evren C, Sar V, Dalbudak E, Durkaya M, Cetin R, Evren B, Cakmak D, Ertem-Vehid H. Childhood trauma and psychopathology among alcohol-dependent men: no interaction with temperament and character. Psychopathology 2011; 44:34-39. [CrossRef]

10. Hodgins DC, Schopflocher DP, el-Guebaly N, Casey DM, Smith GJ, Williams RJ, Wood RT. The association between childhood maltreatment and gambling problems in a community sample of adult men and women. Psychol Addict Behav 2010; 24:548-554.

11. Imperatori $C$, Innamorati $M$, Bersani FS, Imbimbo F, Pompili M, Contardi A, Farina B. The association among childhood trauma, pathological dissociation and gambling severity in casino gamblers. Clin Psychol Psychother 2017; 24:203-211.

12. Kircaburun K, Griffiths MD, Billieux J. Psychosocial factors mediating the relationship between childhood emotional trauma and internet gaming disorder: a pilot study. Eur J Psychotraumatol 2019; 10:1565031. [CrossRef]

13. Yates TM, Gregor MA, Haviland MG. Child maltreatment, alexithymia, and problematic internet use in young adulthood. Cyberpsychol Behav Soc Netw 2012; 15:219-225. [CrossRef]

14. Zhang ZH, Hao JH, Yang LS, Zhang XJ, Sun YH, Hu CL, Ye DQ, Tao FB. The relationship between emotional, physical abuse and Internet addiction disorder among middle school students. Zhonghua Liu Xing Bing Xue Za Zhi 2009; 30:115118. (Chinese) 
15. Zhang ZH, Yang LS, Hao JH, Huang F, Zhang XJ, Sun YH. Relationship of childhood physical abuse and Internet addiction disorder in adolescence: the mediating role of self-esteem. Zhonghua Liu Xing Bing Xue Za Zhi 2012; 33:50-53. (Chinese)

16. Sar V, Akyuz G, Kugu N, Ozturk E, Ertem-Vehid H. Axis I dissociative disorder comorbidity in borderline personality disorder and reports of childhood trauma. J Clin Psychiatry 2006; 67:1583-1590. [CrossRef]

17. Karadag F, Sar V, Tamar-Gurol D, Evren C, Karagoz M, Erkiran M. Dissociative disorders among inpatients with drug or alcohol dependency. J Clin Psychiatry 2005; 66:1247-1253. [CrossRef]

18. Evren C, Sar V, Karadag F, Tamar Gurol D, Karagoz M. Dissociative disorders among alcohol-dependent inpatients. Psychiatry Res 2007; 152:233-241. [CrossRef]

19. Bernardi S, Pallanti S. Internet addiction: a descriptive clinical study focusing on comorbidities and dissociative symptoms. Compr Psychiatry 2009; 50:510-516. [CrossRef]

20. De Berardis D, D’Albenzio A, Gambi F, Sepede G, Valchera A, Conti CM, Fulcheri M, Cavuto M, Ortolani C, Salerno RM, Serroni N, Ferro FM. Alexithymia and its relationships with dissociative experiences and Internet addiction in a nonclinical sample. Cyberpsychol Behav 2009; 12:67-69. [CrossRef]

21. Dvir Y, Ford JD, Hill M, Frazier JA. Childhood maltreatment, emotional dysregulation, and psychiatric comorbidities. Harv Rev Psychiatry 2014; 22:149-161. [CrossRef]

22. Gratz KL, Roemer L. Multidimensional assessment of emotion regulation and dysregulation: development, factor structure, and initial validation of the Difficulties in Emotion Regulation Scale. J Psychopathol Behav Assess 2004; 26:41-54. [CrossRef]

23. Aldao A, Nolen-Hoeksema S, Schweizer S. Emotion-regulation strategies across psychopathology: a meta -analytic review. Clin Psychol Rev 2010; 30:217-237. [CrossRef]

24. Bonn-Miller MO, Vujanovic AA, Boden MT, Gross JJ. Posttraumatic stress, difficulties in emotion regulation, and coping-oriented marijuana use. Cogn Behav Ther 2011; 40:34-44.

25. Fox HC, Axelrod SR, Paliwal P, Sleeper J, Sinha R. Difficulties in emotion regulation and impulse control during cocaine abstinence. Drug Alcohol Depend 2007; 89:298-301. [CrossRef]

26. Fox HC, Hong KA, Sinha R. Difficulties in emotion regulation and impulse control in recently abstinent alcoholics compared with social drinkers. Addict Behav 2008;33:388-394. [CrossRef]

27. Messman-Moore TL, Walsh KL, DiLillo D. Emotion dysregulation and risky sexual behavior in revictimization. Child Abuse Negl 2010; 34:967-976. [CrossRef]

28. Tull MT, Weiss NH, Adams CE, Gratz KL. The contribution of emotion regulation difficulties to risky sexual behavior within a sample of patients in residential substance abuse treatment. Addict Behav 2012; 37:1084-1092. [CrossRef]

29. Blaszczynski A, McConaghy N. Anxiety and/or depression in the pathogenesis of addictive gambling. Int J Addict 1989; 24:337-350.

30. Getty HA, Watson J, Frisch GR. A comparison of depression and styles of coping in male and female GA members and controls. J Gambl Stud 2000; 16:377-391. [CrossRef]
31. Williams AD, Grisham JR, Erskine A, Cassedy E. Deficits in emotion regulation associated with pathological gambling. $\mathrm{Br} \mathrm{J}$ Clin Psychol 2012;51:223-238. [CrossRef]

32. Estevez A, Jauregui P, Sanchez-Marcos I, Lopez-Gonzalez H, Griffiths MD. Attachment and emotion regulation in substance addictions and behavioral addictions. J Behav Addict 2017; 6:534-544. [CrossRef]

33. Torres-Rodriguez A, Griffiths MD, Carbonell X, Oberst U. Internet gaming disorder in adolescence: psychological characteristics of a clinical sample. J Behav Addict 2018; 7:707-718. [CrossRef]

34. Hormes JM, Kearns B, Timko CA. Craving Facebook? Behavioral addiction to online social networking and its association with emotion regulation deficits. Addiction 2014; 109:2079-2088. [CrossRef]

35. Akbari M. Metacognitions or distress intolerance: the mediating role in the relationship between emotional dysregulation and problematic internet use. Addict Behav Rep 2017; 6:128-133.

36. Thompson RA. Emotion regulation: a theme in search of definition. Monogr Soc Res Child Dev 1994; 59:25-52. [CrossRef]

37. Tice DM, Bratslavsky E, Baumeister RF. Emotional distress regulation takes precedence over impulse control: if you feel bad, do it! J Pers Soc Psychol 2001; 80:53-67. [CrossRef]

38. Yu JJ, Kim H, Hay I. Understanding adolescents' problematic Internet use from a social/cognitive and addiction research framework. Comput Human Behav 2013; 29:2682-2689. [CrossRef]

39. Che D, Hu J, Zhen S, Yu C, Li B, Chang X, Zhang W. Dimensions of emotional intelligence and online gaming addiction in adolescence: the indirect effects of two facets of perceived stress. Front Psychol 2017; 8:1206. [CrossRef]

40. Young KS, Rogers RC. The relationship between depression and Internet addiction. Cyberpsych Behav 1998; 1:25-28. [CrossRef]

41. Caplan SE. Problematic Internet use and psychosocial wellbeing: development of a theory-based cognitive-behavioral measurement instrument. Comput Human Behav 2002; 18:553575. [CrossRef]

42. Caplan SE. Theory and measurement of generalized problematic Internet use: a two-step approach. Comput Human Behav 2010; 26:1089-1097. [CrossRef]

43. Gamez-Guadix M, Calvete E, Orue I, Las Hayas C. Problematic Internet use and problematic alcohol use from the cognitivebehavioral model: a longitudinal study among adolescents. Addict Behav 2015; 40:109-114. [CrossRef]

44. LaRose R, Lin C, Eastin MS. Unregulated Internet usage: Addiction, habit, or deficient self-regulation? Media Psychol 2003; 5:225-253. [CrossRef]

45. Tokunaga RS. Perspectives on Internet addiction, problematic Internet use, and deficient self-regulation: contributions of communication research. Annals of the International Communication Association 2015; 39:131-161. [CrossRef]

46. Casale S, Caplan SE, Fioravanti G. Positive metacognitions about Internet use: the mediating role in the relationship between emotional dysregulation and problematic use. Addict Behav 2016; 59:84-88. [CrossRef] 
47. Evren B, Evren C, Dalbudak E, Topcu M, Kutlu N. Relationship of internet addiction severity with probable ADHD and difficulties in emotion regulation among young adults. Psychiatry Res 2018; 269:494-500. [CrossRef]

48. Mo PKH, Chan VWY, Chan SW, Lau JTF. The role of social support on emotion dysregulation and Internet addiction among Chinese adolescents: a structural equation model. Addict Behav 2018; 82:86-93. [CrossRef]

49. Spada MM, Marino C. Metacognitions and emotion regulation as predictors of problematic internet use in adolescents. Clin Neuropsychiatry 2017; 14:59-63.

50. Moulton SJ, Newman E, Power K, Swanson V, Day K. Childhood trauma and eating psychopathology: a mediating role for dissociation and emotion dysregulation? Child Abuse Negl 2015; 39:167-174. [CrossRef]

51. Hebert M, Langevin R, Oussaid E. Cumulative childhood trauma, emotion regulation, dissociation, and behavior problems in schoolaged sexual abuse victims. J Affect Disord 2018; 225:306-312.

52. Young KS. Caught in the Net. New York: John Wiley and Sons, 1998.

53. Ngai SS. Exploring the validity of the Internet addiction test for students in Grades 5-9 in Hong Kong. Int J Adolesc Youth 2007; 13:221-237. [CrossRef]

54. Boysan M, Kuss DJ, Barut Y, Aykose N, Gulec M, Ozdemir O. Psychometric properties of the Turkish version of the internet addiction test (IAT). Addict Behav 2017; 64:247-252. [CrossRef]

55. Bernstein EM, Putnam FW. Development, reliability and validity of a dissociation scale. J Nerv Ment Dis 1986; 174:727-735.

56. Yargic LI, Tutkun H, Sar V. The reliability and validity of the Turkish version of the Dissociative Experiences Scale. Dissociation 1995; 8:10-13.

57. Sar V, Kundakci T, Kiziltan E, Bakim B, Yargic LI, Tutkun H. The reliability and validity of the Turkish version of the Dissociative Experiences Scale (DES-II). Proceedings of the 33rd National Congress of Psychiatry, Antalya, Turkey. Psychiatric Association of Turkey, Ankara, 1997, 55-64. (Turkish)

58. Bernstein DP, Fink L, Handelsman L, Foote J, Lovejoy M, Wenzel K, Sapareto E, Ruggiero J. Initial reliability and validity of a new retrospective measure of child abuse and neglect. Am J Psychiatry 1994; 151:1132-1136. [CrossRef]

59. Bernstein DP, Ahluvalia T, Pogge D, Handelsman L. Validity of the childhood trauma questionnaire in an adolescent psychiatric population. J Am Acad Child Adolesc Psychiatry 1997; 36:340348. [CrossRef]

60. Sar V, Ozturk E, Ikikardes E. Validity and reliability of the Turkish version of Childhood Trauma Questionnaire. Turkiye Klinikleri J Med Sci 2012; 32:1054-1063. (Turkish) [CrossRef]

61. Gratz KL, Tull MT. Emotion regulation as a mechanism of change in acceptance- and mindfulness-based treatments: In Baer RA (editor). Assessing Mindfulness and Acceptance Processes in Clients: Illuminating the Theory and Practice of Change. Oakland, CA: New Harbinger Publications, 2010, 107133.
62. Gratz KL, Rosenthal MZ, Tull MT, Lejuez CW, Gunderson JG. An experimental investigation of emotion dysregulation in borderline personality disorder. J Abnorm Psychol 2006; 115:850-855.

63. Ruganci RN, Gencoz T. Psychometric properties of a Turkish version of the Difficulties in Emotion Regulation Scale. J Clin Psychol 2010; 66:442-455. [CrossRef]

64. Chu JA, Dill DL. Dissociative symptoms in relation to childhood physical and sexual abuse. Am J Psychiatry 1990; 147:887-892.

65. Gershuny BS, Thayer JF. Relations among psychological trauma, dissociative phenomena, and trauma-related distress: a review and integration. Clin Psychol Rev 1999; 19:631-657. [CrossRef]

66. Sar V, Akyuz G, Dogan O. Prevalence of dissociative disorders among women in the general population. Psychiatry Res 2007; 149:169-176. [CrossRef]

67. Gladstone GL, Parker GB, Mitchell PB, Malhi GS, Wilhelm K, Austin MP. Implications of childhood trauma for depressed women: an analysis of pathways from childhood sexual abuse to deliberate self-harm and revictimization. Am J Psychiatry 2004; 161:1417-1425. [CrossRef]

68. Ko $\mathrm{CH}$, Yen JY, Yen CF, Lin HC, Yang MJ. Factors predictive for incidence and remission of Internet addiction in young adolescents: a prospective study. Cyberpsychol Behav 2007; 10:545-551. [CrossRef]

69. Huang RL, Lu Z, Liu JJ, You YM, Pan ZQ, Wei Z, He Q, Wang ZZ. Features and predictors of problematic internet use in Chinese college students. Behav Inf Technol 2009;28:485-490. [CrossRef]

70. Rademaker AR, Vermetten E, Geuze E, Muilwijk A, Kleber RJ. Self-reported early trauma as a predictor of adult personality: a study in a military sample. J Clin Psychol 2008; 64:863-875.

71. Schwandt ML, Heilig M, Hommer DW, George DT, Ramchandani VA. Childhood trauma exposure and alcohol dependence severity in adulthood: mediation by emotional abuse severity and neuroticism. Alcohol Clin Exp Res 2013; 37:984-992. [CrossRef]

72. Tutkun H, Savas HA, Zoroglu SS, Esgi K, Herken H, Tiryaki N. Relationship between alexithymia, dissociation and anxiety in psychiatric outpatients from Turkey. Isr J Psychiatry Relat Sci 2004; 41:118-124.

73. Gross EF, Juvonen J, Gable SL. Internet use and well-being in adolescence. J Soc Issues 2002; 58:75-90. [CrossRef]

74. Ko CH, Yen JY, Yen CF, Chen CS, Chen CC. The association between Internet addiction and psychiatric disorder: a review of the literature. Eur Psychiatry 2012; 27:1-8. [CrossRef]

75. Selfhout MH, Branje SJ, Delsing M, ter Bogt TF, Meeus WH. Different types of Internet use, depression, and social anxiety: the role of perceived friendship quality. J Adolesc 2009; 32:819833. [CrossRef]

76. Greenberg L. The therapeutic relationship in emotion-focused therapy. Psychotherapy (Chic) 2014; 51:350-357. [CrossRef]

77. Allen NB, Chambers R, Knight W; Melbourne Academic Mindfulness Interest Group. Mindfulness-based psychotherapies: a review of conceptual foundations, empirical evidence and practical considerations. Aust N Z J Psychiatry 2006; 40:285-294. [CrossRef] 